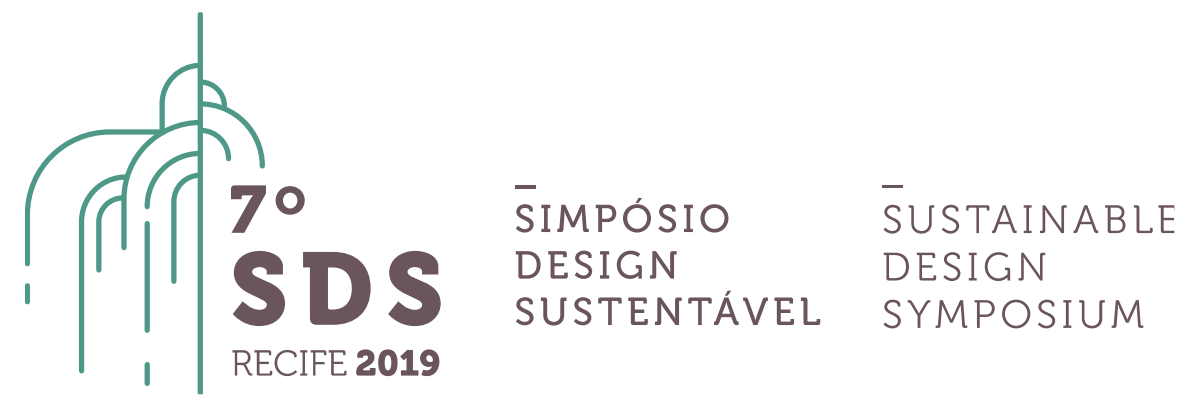

\title{
O design como mediador na produção artesanal indígena em Barcelos, Amazonas
}

\author{
$<$ André Luiz Fronza $>^{1},<$ Regina Lara Silveira Mello ${ }^{2}$ \\ ${ }^{1}<$ Universidade Presbiteriana Mackenzie, aluno na Pós-graduação em Educação, \\ Arte e História da Cultura, andrefronza778@hotmail.com> \\ ${ }^{2}<$ Universidade Presbiteriana Mackenzie, professora pesquisadora na Pós-graduação em Educação, \\ Arte e História da Cultura, regina.mello@mackenzie.br>
}

\begin{abstract}
Resumo. Para inserir o artesanato tradicional no mercado contemporâneo $e$ garantir o desenvolvimento econômico e social de comunidades artesãs, designers são contratados por instituições para desenvolver projetos a fim de promover inovação em territórios únicos. Neste contexto, o artigo tem como objetivo analisar o processo e os resultados alcançados da atuação do designer Sérgio Matos e do Sebrae Amazonas no desenvolvimento sustentável da comunidade indígena de Barcelos, Amazonas, sob a chancela do Núcleo de Arte e Cultura Indígena de Barcelos. A pesquisa adotada é qualitativa, de caráter exploratório e descritivo. Conclui-se que o projeto foi eficiente, pois a proposta não focava somente o desenvolvimento de novos produtos, mas também na capacitação da comunidade para o empreendedorismo. $O$ designer atuou como mediador, houve uma melhoria da qualidade do produto, adaptou-se sua função e deslocou-os de um segmento para outro mais valorizado pelo mercado.
\end{abstract}

Palavras-chave. Design; Artesanato; Mediador; Desenvolvimento local; Indígena; Sustentabilidade.

\section{Introdução}

$\mathrm{Na}$ atual fase histórica, que se caracteriza por altos índices de produção, consumo e descarte de artefatos industriais, torna-se imperativo a necessidade de gerar conhecimentos a partir da perspectiva de projetar na esfera artesanal. Diante de um mercado globalizado abarrotado de produtos industriais parecidos, existe uma lacuna para desenvolver produtos artesanais inovadores. Além de ser imprescindível o desenvolvimento de pesquisas que se configuram em instrumentos eficazes para o desenvolvimento sustentável de comunidades originárias e tradicionais.

Neste contexto, na transição do século XX para o XXI, começou timidamente um movimento dos designers ao interior do país para auxiliar na revitalização do artesanato para o 
mercado contemporâneo (BORGES, 2011). Para tanto, algumas instituições como o Sebrae, contratam estes profissionais para realizar intervenções com o objetivo de promover inovação para garantir o desenvolvimento social e econômico das comunidades artesãs.

Essas ações envolvem diversos profissionais, desde técnicos para solucionar problemas específicos, até aqueles especializados em divulgar os novos produtos que resultam do projeto. 0 designer, por ser o ator social que lida com as interações cotidianas dos seres humanos com seus artefatos, pode ser parte da solução. Seu papel é oferecer soluções criativas aos problemas rumo a sustentabilidade (MANZINI, 2008).

Assim, o artigo tem como objetivo analisar o processo e os resultados alcançados da atuação do designer no desenvolvimento sustentável de comunidades tradicionais inseridas em territórios únicos, distantes dos grandes centros urbanos.

Para o estudo de caso foi escolhido a comunidade indígena de Barcelos, Amazonas, organizada sob a chancela do Núcleo de Arte e Cultura Indígena de Barcelos (NACIB). A região apresenta fortes características históricas e culturais peculiares para o estudo da relação sistêmica entre design e desenvolvimento social, tendo a criatividade e o território como fomentadores dessa relação. O grupo contou com a atuação do designer Sérgio Matos e da instituição Sebrae.

A pesquisa adotada é qualitativa, de caráter exploratório e descritivo. Segundo Gil (2008) as pesquisas descritivas, juntamente com as exploratórias, geralmente são realizadas por pesquisadores sociais preocupados com a ação prática. Para a fundamentação teórica utilizou-se os autores Manzini (2008) e Bonsiepe (2012) que discorrem sobre sustentabilidade e design, e Borges (2011) e Krucken (2009) que explicitam a união do design, artesanato e a valorização do território local no projeto. Recorreu-se também a depoimentos dos atores sociais participantes deste projeto, como o designer, a coordenadora do projeto e do grupo de artesãs, divulgados em matérias jornalísticas, seminários e vídeos no YouTube.

\section{Revisão bibliográfica}

\subsection{Design além da estética, rumo a sustentabilidade}

A partir dos anos 1990, com a explosão do termo na mídia, o conceito de design perdeu seu significado original, de modo que, na opinião pública, passou a ser associado apenas aos aspectos estéticos-formais, ao produto caro e até supérfluo. Para Bonsiepe (2012) o conceito de design vai muito além, se encontra na intersecção entre a cultura da vida cotidiana, a tecnologia e a economia. "Enfoca o caráter operacional dos artefatos materiais e semióticos, interpretando a sua função e a funcionalidade não em termos de eficiência física [...] mas em termos de comportamento incorporado em uma dinâmica cultural e social"' (2012, p. 19).

Neste terreno, o foco do design amplia quando passamos a considerar a relação entre a rápida evolução tecnológica, as matérias-primas e o fenômeno da globalização. Isso exige uma nova postura na concepção de artefatos e de produtos-serviços, devido ao excesso de mercadorias e de um ambiente saturado de descartes em limites inaceitáveis. Assim, essa área exige o trabalho interdisciplinar, não se limita aos aspectos ambientais, mas considera também a sustentabilidade social e econômica (BONSIEPE, 2012).

Para Manzini (2008), a sustentabilidade poderá ser atingida por meio de processos de descontinuidades sistêmicas, isso significa romper com as tendências dominantes em termos de produção, consumo e estilo de vida, criando e experimentando novas possibilidades. Essas descontinuidades "atingirá todas as dimensões do sistema sociotécnico no qual vivemos: a física (fluxos materiais e energéticos), a econômica e institucional (a relação entre os atores sociais) e a 
ética, estética e cultural (os valores e juízos de qualidade que the darão legitimidade social)" (MANZINI, 2008, p. 19).

O autor acredita que os designers podem ser parte desta solução, por serem os atores sociais que lidam com as interações cotidianas dos seres humanos com seus artefatos. Seu papel é oferecer soluções criativas aos problemas rumo a sustentabilidade. Além de promover a variedade, visto que a sustentabilidade é praticamente sinônimo de diversidade biológica, cultural, organizacional e tecnológica.

\subsection{Design, a dimensão local e o artesanato}

É importante dizer que a visão sistêmica do design para a sustentabilidade contempla o âmbito socioambiental, o território é considerado como modelo de referência que une o social com o ambiente geográfico local (MORAES, 2010). A maioria dos objetos de uso cotidiano e de produção local, possui um forte vínculo com seu território de origem e com a comunidade que os gerou, desde a escolha das matérias-primas e processos até o uso de elementos culturais.

Para discutir essa questão, tomou-se como base a abordagem do design e território de Krucken (2009), que visa valorizar os recursos e produtos locais que surgem a partir da vocação de uma região. A autora apresenta oito ações essenciais para promover o desenvolvimento sustentável local a grande prazo: reconhecer as qualidades do produto e do território; ativar as competências situadas no território; comunicar o produto e o território; proteger a identidade local e o patrimônio material e imaterial; apoiar a produção local; promover sistemas de produção e de consumo sustentáveis; desenvolver novos produtos e serviços que respeitem a vocação e valorizem o território; e, consolidar redes no território.

Essas ações podem ser vistas como processos para orientar o desenvolvimento econômico, social e ambiental, respeitando questões locais, como culturas e tradições. Um bom exemplo de aplicação pode ser visto no artesanato.

Na transição do século XX para o XXI ocorreu o ressurgimento do artesanato como meio de produção possível e de poética própria. Nessa época começou timidamente um movimento dos designers ao interior do país para auxiliar na revitalização. Segundo Borges (2011), o profissional pode atuar em vários pontos neste caso:

\footnotetext{
melhoria da qualidade de objetos; aumento da percepção consciente dessa qualidade pelo consumidor; redução de matéria-prima; redução ou racionalização de mão de obra; otimização de processos de fabricação; combinação de processos e materiais; interlocução sobre desenhos e cores; adaptação de funções; deslocamento de objetos de um segmento para outro mais valorizado pelo mercado; intermediação entre comunidades e mercado; comunicação dos atributos intangíveis dos objetos artesanais; facilitação do acesso dos artesãos ou de sua produção à mídia; contribuição na gestão estratégica das ações; explicitação da história por trás dos objetos artesanais (BORGES, 2011, p. 129).
}

Neste contexto, o designer atua como um mediador e facilitador junto a grupos e comunidades de artesãos, a fim de despertar a autoria e autonomia dos envolvidos. Como é um campo recém explorado, os projetos ainda são desenvolvidos de forma bastante intuitiva, de acordo com as experiências acumuladas dos profissionais.

\section{Estudo de caso}

\subsection{Núcleo de Arte e Cultura Indígena de Barcelos}

Barcelos é um município do Estado do Amazonas, localizado na região do médio Rio Negro, no Noroeste Amazônico, a uma distância de 490 km de Manaus por via fluvial. Fundada em 1728, foi a primeira sede da Capitania de São José do Rio Negro. Desde o início da colonização recebeu 
populações indígenas do Alto Rio Negro para formar os núcleos missionários. No final do século XIX o ciclo da borracha trouxe imigrantes nordestinos. A população local é fruto da miscigenação de portugueses, nordestinos e escravos indígenas e negros (BARRA; DIAS, 2013).

Nas últimas duas décadas a migração indígena para a área urbana de Barcelos intensificou. Com o propósito de tomar conta de seu futuro e de seus povos, alguns ativistas indígenas agiram e formaram associações para a reivindicação do reconhecimento de sua ancestralidade. Hoje, na cidade, encontra-se as etnias Tukano, Baniwa, Baré, Desana, Piratapuia, Tariana, Arapaço, Cabarí, Yanomami, Canamar, Lanaua e Cubeu. Os Baré, Baniwa e Tukano constituem os maiores grupos étnicos (PERES, 2003).

Em 1999 foi fundado a Associação Indígena de Barcelos (ASIBA) e em 2012 o Núcleo de Arte e Cultura Indígena de Barcelos (NACIB). Este último surgiu com o objetivo de promover estratégias de valorização da cultura tradicional e comercialização dos produtos regionais de forma sustentável nas áreas de artesanato e agricultura indígena para a geração de renda. 0 núcleo tem como coordenadora geral, Dinalva Dias Campos, da etnia Tariana (NACIB, 2014).

O artesanato produzido pelas comunidades indígenas e ribeirinhas é de tradição, uma vez que é transmitido de geração a geração. É feito com materiais disponíveis no local, sendo o principal a fibra de piaçaba (Leopoldina piassaba), material abundante na região. Também são usados cipó-ambé, cipó-titica, sementes naturais, madeiras e fibras de arumã. O núcleo, que reúne indígenas das etnias Baré, Baniwa, Tariano, Tukano e Tuyuca, produz artesanato com as técnicas do trançado e do entalhe (NACIB, 2014).

Antes da intervenção do design as artesãs produziam peças pequenas, como vasos, cestas, biojóias, bolsas, peças decorativas e utilitárias (figura 1). Os preços variavam de $R \$ 5$ a $R \$ 50$. A comercialização ficava restrita às feiras da cidade, a venda aumentava significativamente durante o Festival do Peixe Ornamental de Barcelos, evento anual que estimula o turismo do interior do Amazonas, porém isso ficava restrito aos meses de janeiro, quando ocorria o festival (SEMINÁRIO ARTESOL, 2019).

Figura 1 - Produtos do Núcleo de Arte e Cultura Indígena de Barcelos (NACIB)

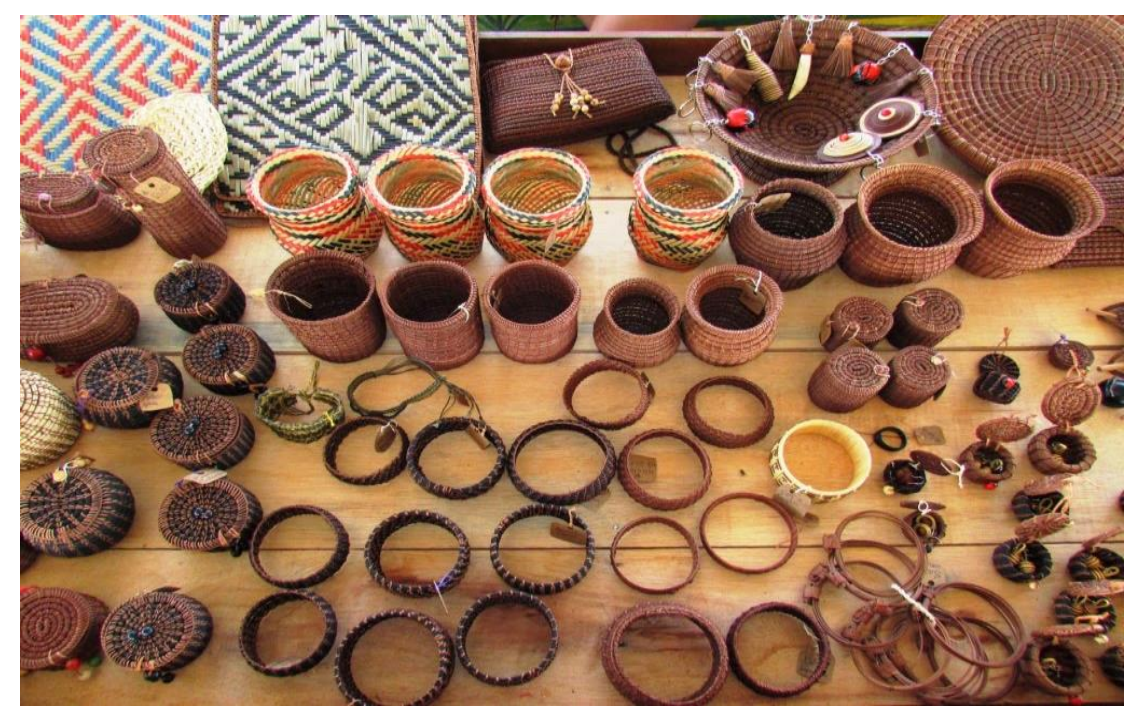

Fonte: NACIB. Disponível em: http://nacibam.blogspot.com/ Acesso em: 01 abr. 2019.

\subsection{As intervenções do design e do Sebrae}

Em 2014, dois anos após a formação, o NACIB buscou parceria com o Sebrae Amazonas para dar suporte a produção. Segundo Dinalva, coordenadora da associação, o artesanato 
indígena tinha pouco espaço no mercado, o grupo passou por dificuldades financeiras no começo (AMAZONAS NOTÍCIAS, 2018).

Foi através do programa Brasil Original, com sede em Manaus e desenvolvido pelo SebraeAM, que a comunidade passou a receber diversas capacitações ao longo de três anos (2014 a 2016). Primeiro os artesãos receberam orientação no processo criativo do produto. Em seguida, foram auxiliados na área promocional, por meio da comercialização das peças em lojas e feiras. $O$ programa tem como objetivo reposicionar o artesanato no mercado para que os produtos sejam valorizados (ASSOCIAÇÃO ZAGAIA AMAZÔNIA, 2019).

Neste caso, a estratégia do Sebrae-AM foi redesenhar o produto para migrar do mercado local, onde estava saturado e desvalorizado, para o mercado de luxo nacional, a fim de potencializar o seu valor. Essa ação é uma das mencionadas por Krucken (2009), as qualidades locais precisam ser valorizadas, se o produto não é bem aceito no mercado, será que não "é necessário redesenhá-lo ou mudar de mercado para que o seu valor seja potencializado?" (KRUCKEN, 2009, p. 101).

No começo de 2015 o designer Sérgio Matos, contratado pelo Sebrae-AM, chegou em Barcelos para conhecer a cultura local e co-criar com as artesãs novos produtos. Sérgio formou-se em Design Industrial na Universidade Federal de Campina Grande, Paraíba. Fundou em 2010 o Sérgio J. Matos Estúdio Design, em Campina Grande, onde produz móveis autorais, como pufes, sofás, poltronas, cadeiras, luminárias, mesas e vasos.

Sua produção está, em praticamente todos os casos, associada com a ideia de valorização do regional e artesanal, da identidade cultural brasileira de modo geral. Para ele, é importante valorizar a história, a memória, os laços afetivos e os saberes e fazeres ancestrais dos povos (VIERA, 2015). A junção do design com artesanato é tão importante e natural para Sérgio que, em parceria com o Sebrae, passou a fazer consultorias voltadas às comunidades artesãs no Norte, Nordeste e Centro-Oeste para criar novos produtos e novas oportunidades de negócio.

Sua atuação junto a grupos de artesãos está estruturada em 11 etapas: "pesquisa local; levantamento de materiais; levantamento de temas para o conceito; geração de ideias; aprimoramento das ideias; testes; protótipos; peça piloto; produto final; divulgação; e lançamento" (SERAFIM; CAVALCANTI; FERNANDES, 2016, p. 38). Seu foco recai no desenvolvimento de produtos, conhecimentos sobre empreendedorismo, gestão do grupo e vendas são realizados através de outros profissionais contratados. 


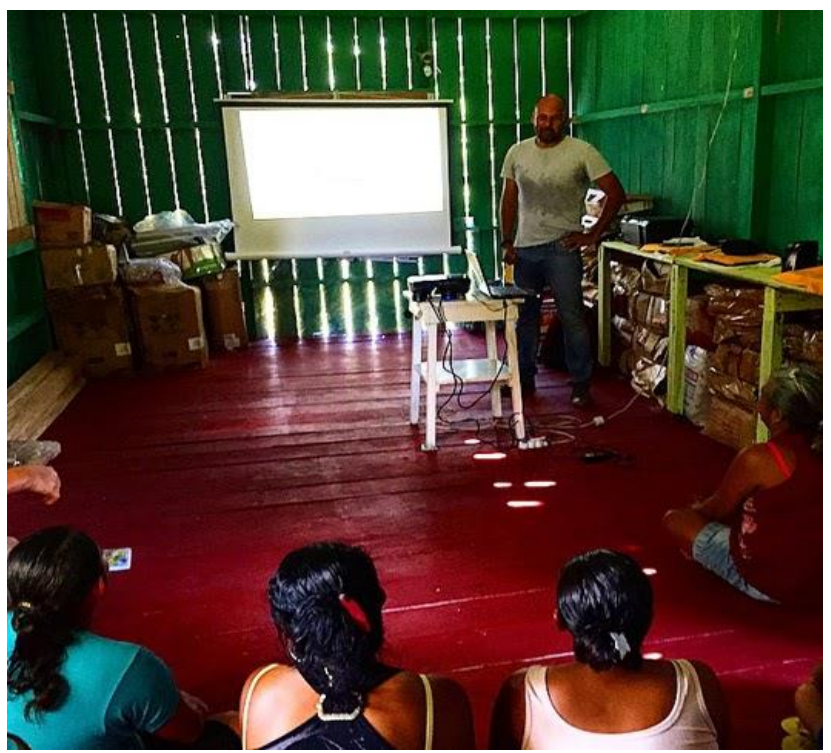

Fonte: Sérgio Matos. Disponível em: http://sergiojmatos.blogspot.com/2015/03/a-semente-do-designgermina.html. Acesso em: 02 abr. 2019.

De acordo com Sérgio Matos (2015), a consultoria de design em Barcelos (figura 2) teve como objetivo fortalecer a vocação artesanal e promover novos rumos para as populações indígenas e ribeirinhas. Isso "abre rotas de criatividade, alarga caminhos que levam à autoestima e à valorização do feito à mão. Resgata, também, o orgulho das raízes ancestrais presentes na cultura" (MATOS, 2015).

Desse encontro nasceu uma coleção de peças grandes para a casa, composta por cestos, fruteiras e peças que podem servir de centro de mesa ou bandejas (figura 3). Sérgio elegeu a vitória-régia, planta icônica da Amazônia que flutua sobre as águas dos rios, para servir de inspiração para o projeto. A fruteira é baseada na flor da vitória-régia, com suas pétalas sobrepostas, e as bandejas na forma da planta.

Ao comparar os produtos que eram feitos com os novos é possível perceber que a técnica de produção não foi interferida, assim como a matéria-prima, que continua sendo a piaçava. Estes elementos estão fortemente associados a comunidade, fazem parte de sua história e cultura, atuam como marcadores de identidade. Sérgio reconheceu estas qualidades do produto e do território, assim não interferiu. De acordo com Krucken (2009), é preciso "compreender o espaço onde nasce o produto, sua história e suas qualidades, associadas ao território e à comunidade de origem" (KRUCKEN, 2009, p. 99). A contribuição neste caso foi a percepção do potencial da paisagem local, com a vitória-régia e sua flor, para servir de base para a criação da coleção.

Figura 3 - Artesãs do NACIB e os produtos co-criados com Sérgio Matos 


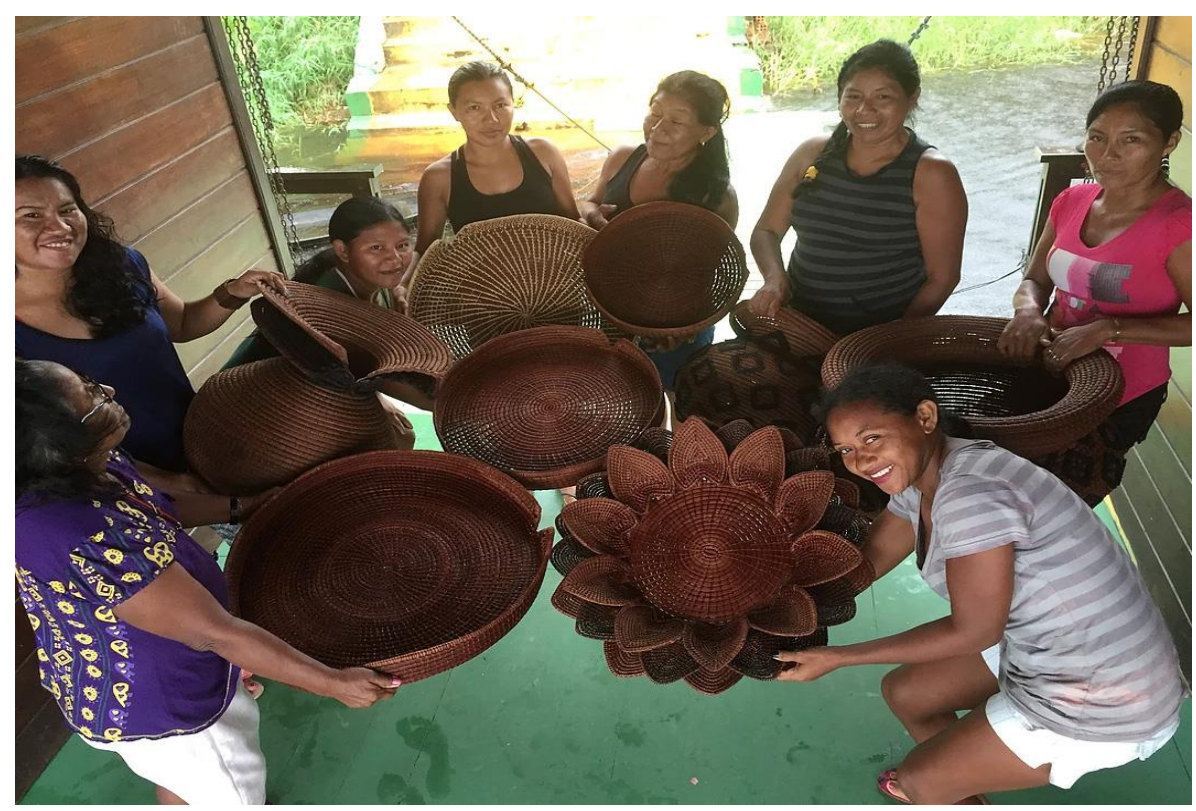

Fonte: Associação Amazônia Zagaia. Disponível em: https://www.amazonzagaia.com.br/projetos. Acesso em: 11 de mar. 2019.

A principal atuação desta intervenção foi no pilar econômico e social do desenvolvimento sustentável, já que as ações tiveram foco na produção de artefatos para novos mercados e na capacitação das artesãs para as vendas. O pilar ambiental já estava bem resolvido, uma vez que o material utilizado, a piaçava, é de fonte natural e renovável, além de ser abundante na região. Mesmo que os novos produtos demandam uma quantidade maior de matéria-prima, a produção e extração de piaçava em Barcelos é regulamentado e fiscalizado pelo Instituto de Desenvolvimento Agropecuário e Florestal Sustentável do Amazonas (IDAM), para garantir que os ciclos naturais não sejam perturbados além dos limites de resiliência dos ecossistemas.

É importante destacar que a imagem profissional do Sérgio Matos, consolidada através da mídia especializada e dos prêmios que já acumulou, como do Museu da Casa Brasileira, if Design Award e Design Excellence Brasil, também provoca um impacto positivo no âmbito econômico desse projeto. Uma vez que a comercialização dos produtos ganha destaque por terem sua participação na criação. Além disso, a divulgação é mais abrangente graças às suas redes de contato e das redes sociais, como Instagram e Facebook.

O Sebrae e a coordenadora do núcleo apresentaram os produtos da coleção em agosto de 2015 na Paralela Gift em São Paulo (figura 4), feira anual de design autoral, alta decoração e artesanato contemporâneo, que acontece no Parque Ibirapuera. Tanto Sérgio quanto o Sebrae, durante os três anos de atuação, apoiaram a participação das comunidades em feiras de comercialização. Porém, estes agentes sociais não comercializam os produtos, o contato de venda e negociação é feito diretamente com o NACIB, não há intermediários, consequentemente os lucros chegam diretamente às artesãs.

Figura 4 - Lílian Simões, Dinalva Campos e artesão no lançamento da coleção na Paralela Gift 


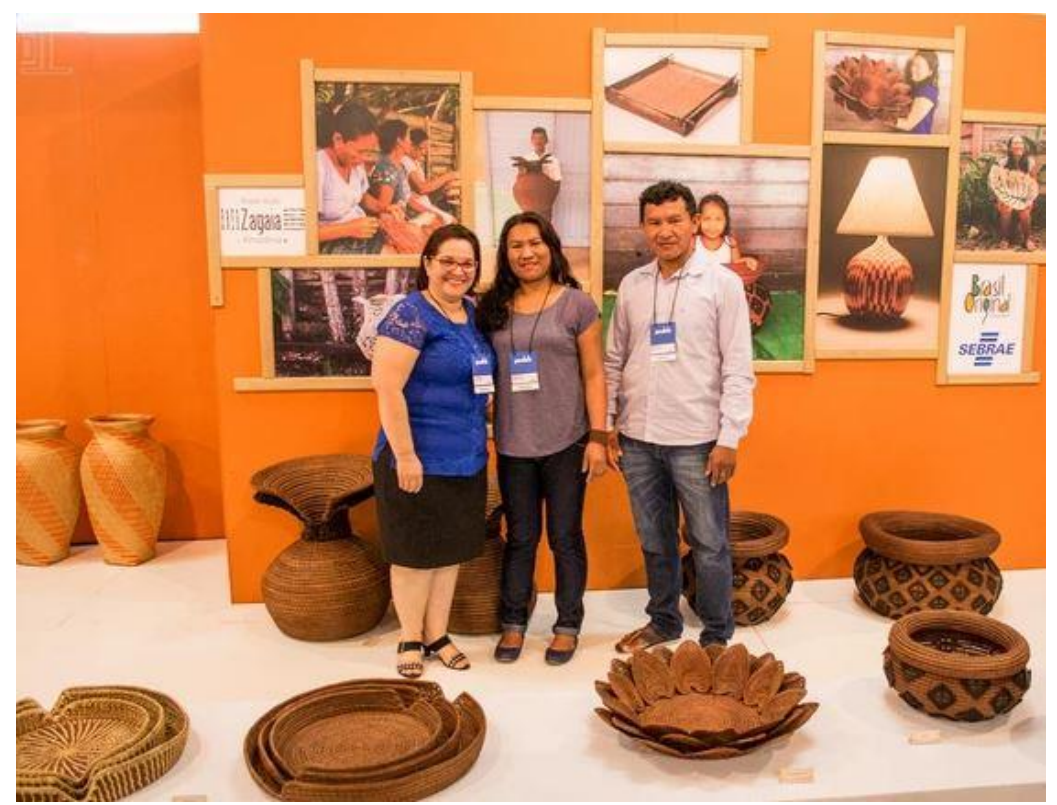

Fonte: Associação Amazônia Zagaia. Disponível em: https://www.amazonzagaia.com.br/projetos. Acesso em: 06 de abr. 2019.

Além de criarem uma nova coleção, o designer e a instituição ajudaram a comunidade a desenvolver e consolidar redes de contato para facilitar o acesso ao mercado. Isso promove o empoderamento comunitário, fortalece os artesãos, incrementa a participação e desenvolve relações mutuamente benéficas. Krucken (2009) diz que é preciso desenvolver redes, tanto internas quanto externas, para acessar o mercado consumidor. Não adianta ter um bom produto se não chega no mercado, esse é um ponto positivo da intervenção.

As peças da coleção também estiveram presentes na exposição inaugural do Centro Sebrae de Referência do Artesanato Brasileiro (CRAB) intitulada "Origem Vegetal", com curadoria de Adélia Borges no Rio de Janeiro em 2016. Também houve divulgação em revistas nacionais de grande circulação, como Casa Claudia, Casa Jardim e Casa Vogue.

\subsection{Os resultados}

Com o fim do projeto em 2016, o NACIB passou a trilhar seu próprio caminho. De acordo com Lílian Simões (apud ZAMPIRON, 2019), gestora do Sebrae-AM, o impacto foi positivo. Com a capacitação, as artesãs passaram a fabricar itens com maior valor agregado, que custam até $\mathrm{R} \$$ 600. Dinalva, coordenadora do núcleo, diz que o artesanato hoje "não complementa mais a renda, a renda é direta" (TESOUROS DA AMAZÔNIA, 2016).

A abertura de mercado fez com que a demanda crescesse, assim como a mão de obra. Segundo Sérgio (SEMINÁRIO ARTESOL, 2019) "o grupo que era de 12 mulheres hoje são 54 homens e mulheres trabalhando, o artesanato era uma função só da mulher, hoje os homens trabalham juntos com elas, porque tá gerando renda".

A comunidade passou a valorizar o próprio trabalho, o sentido de pertença e orgulho foi restabelecido. $O$ desenvolvimento pessoal e coletivo foi levado em consideração, Sérgio promoveu oficinas para estimular as capacidades pessoais e reforçar o tecido social para trocar habilidades e conhecimentos entre as mulheres.

Segundo Lílian (apud ZAMPIRON, 2019), hoje as artesãs empregam efetivamente os conhecimentos adquiridos pelo Sebrae. Em 2018 o artesanato foi comercializado na High Design Expo em São Paulo, uma das maiores feiras de design de interiores do Brasil. A coordenadora Dinalva esteve presente de forma autônoma, sem auxílio do Sebrae. Elas entenderam todos os 
passos da cadeia produtiva. Isso promoveu a autonomia do grupo para decidir todo o processo, da seleção da matéria-prima ao cálculo de preço de uma peça, além de emitir nota fiscal e enviar o produto.

Este último diz respeito à logística, ponto frágil do projeto que precisa de uma melhor solução a longo prazo. Com a abertura de mercado, o produto passou a ser vendido para grandes centros urbanos, distantes do local de produção, como São Paulo, Rio de Janeiro, Florianópolis e Porto Alegre. Consequentemente houve o aumento da demanda por transporte, as peças são levadas de Barcelos até Manaus de barco, o que demora dias e tem custo elevado. Depois são transportadas de avião e caminhão até o destino final.

Essa desregionalização gera custos ambientais elevados e encarece o produto. É necessário inovar na intermediação dos produtos com o desenvolvimento de infraestruturas que suportem modelos sustentáveis e vantajosos para os consumidores e produtores. Neste contexto, é necessário que haja apoio de políticas públicas, para fortalecer as construções territoriais, como afirma Krucken (2009), nas ações para valorizar produtos e identidades locais.

\section{Considerações finais}

Não existe receita única para elaborar projetos de desenvolvimento sustentável do artesanato local. Sob a perspectiva do design, Krucken (2009) e Borges (2011) apresentam inúmeras ações como visto neste estudo. Observa-se que a intervenção do designer e do Sebrae no Núcleo de Arte e Cultura Indígena de Barcelos foi eficiente, pois a proposta não estava somente no desenvolvimento de novos produtos, mas também na capacitação da comunidade para vendas, construção de redes de contato, valorização do artesão e de toda a comunidade envolvida, o que estimula o desenvolvimento a longo prazo.

Com a atuação do designer houve uma melhoria da qualidade do produto. Adaptou-se a função dos objetos, que antes atendiam as necessidades da comunidade, e deslocou os produtos de um segmento para outro mais valorizado pelo mercado. A imagem da marca do designer facilitou o acesso dos artesãos ao mercado e à mídia especializada, o que promoveu a criação de redes de contato. Na mídia, digital e impressa, Sérgio Matos comunicou através de entrevistas e palestras os atributos intangíveis dos objetos desenvolvidos, como cultura, história e tradição.

Outro fator a ser considerado é o tempo de duração do projeto, em três anos foi possível acompanhar e avaliar os resultados com mais detalhe e clareza em vários eixos. Assim é possível promover autonomia e autogestão dos grupos, contribui-se para a transformação social efetiva. Se fosse em um tempo menor é bem provável que as ações seriam mais pontuais, restritas ao desenvolvimento de novos produtos.

A política assistencialista, praticada décadas atrás em algumas comunidades, é substituída pelo incentivo à organização coletiva, estimula-se o empreendedorismo rumo à autonomia. Esse enfoque produtivista do design com o artesanato, proporciona a circulação do trabalho das comunidades artesãs, já que possibilita sua inserção no capitalismo por meio de seus saberes e fazeres tradicionais atrelado ao território.

O designer atua como mediador cultural, uma vez que promove o deslocamento dos artefatos para novos mercados, une a comunidade produtora e o mercado consumidor. Isso promove autonomia financeira dos artesãos, o que evita a migração destes para centros urbanos para desempenharem funções nas quais não encontrem correspondências pessoais, além de evitar que vivem à margem da cidade.

A contribuição social, econômica e ambiental do design, que neste caso busca atribuir ao artesanato tradicional, enriquece e estimula novas políticas de fomento ao artesanato. Isso 
comprova que, cada vez mais, design e artesanato devem andar juntos e fortalecerem como atividades promissoras rumo ao desenvolvimento sustentável local.

\section{Referências}

AMAZONAS NOTÍCIAS. Apoio do Sebrae eleva em mais de $\mathbf{1 0 0 \%}$ valor de venda do artesanato produzido por indígenas de Barcelos. Amazonas, 06 fev. 2018. Disponível em: https://amazonasnoticias.com.br/apoio-do-sebrae-eleva-em-mais-de-100-valor-de-venda-doartesanato-produzido-por-indigenas-de-barcelos/. Acesso em: 11 mar. 2019.

ASSOCIAÇÃO ZAGAIA AMAZÔNIA. Brasil Original Amazonas. Disponível em: https://www.amazonzagaia.com.br/brasil-original. Acesso em: 11 mar. 2019.

BARRA, Camila Sobral; DIAS, Carla (Org.). Barcelos indígena e ribeirinha: um perfil socioambiental. São Paulo: Instituto Socioambiental, 2013.

BONSIEPE, Gui. Design: como prática de projeto. São Paulo: Blucher, 2012.

BORGES, Adélia. Design e Artesanato: o caminho brasileiro. São Paulo: Ed. Terceiro Nome, 2011.

GIL, Antonio Carlos. Métodos e técnicas de pesquisa social. São Paulo: Atlas, 2008.

KRUCKEN, Lia. Design e território: valorização de identidades e produtos locais. São Paulo: Studio Nobel, 2009.

MANZINI, Ezio. Design para a inovação social e sustentabilidade: comunidades criativas, organizações colaborativas e novas redes projetuais / Ezio Manzini; [coordenação de tradução Carla Cipolla; equipe Elisa Spampinato, Aline Lys Silva]. Rio de Janeiro: E-papers, 2008.

MATOS, Sérgio. A semente do design germina. Blog Sérgio J. Matos. 31 mar. 2015. Disponível em: http://sergiojmatos.blogspot.com/2015/03/a-semente-do-design-germina.html. Acesso em: 02 abr. 2019.

MORAES, Dijon De. Metaprojeto: o design do design. São Paulo: Blucher, 2010.

NACIB. Apresentação breve do Núcleo. Barcelos, 01 jun. 2014. Disponível em: http://nacibam.blogspot.com/. Acesso em: 08 mar. 2019.

PERES, Sidnei. Cultura, política e identidade na Amazônia: o associativismo indígena no Baixo Rio Negro. São Paulo: Unicamp, 2003.2 Disponível em: http://www.revista.ufpe.br/revistaanthropologicas/index.php/revista/article/viewFile/23/26.

Acesso em: 08 mar. 2019.

SEMINÁRIO ARTESOL: Sérgio Matos. Rio de Janeiro, 2019. 1 vídeo (22 min). Disponível em: https://www.youtube.com/watch?v=1-n-SWwLXD8\&t=5s. Acesso em: 02 abr. 2019.

SERAFIM, Elisa Feltran; CAVALCANTI, Virginia; FERNANDES, Dulce Maria Paiva; "Design e artesanato no Brasil: reflexões sobre modelos de atuação do design junto a grupos de produção artesanal", p. 30-41. In: Anais do 5o Simpósio Brasileiro de Design Sustentável [Blucher Design Proceedings, v.2, n.5]. São Paulo: Blucher, 2016. Disponível em: http://pdf.blucher.com.br.s3-saeast-1.amazonaws.com/designproceedings/sbds15/1st601d.pdf. Acesso em: 03 abr. 2019.

TESOUROS DA AMAZÔNIA. [S. I.: s. n.], 2016. 1 vídeo $(2 \mathrm{~min})$. Disponível em: https://www.youtube.com/watch?v=F-8KoqJ8lwg. Acesso em: 02 abr. 2019.

VIERA, Ivan. Entrevista Sérgio J. Matos. A CASA museu do objeto brasileiro, 10 abr. 2015. Disponível em: http://www.acasa.org.br/biblioteca_texto.php?id=542. Acesso em: 28 fev. 2019. 
ZAMPIRON, Caroline. [Caso de sucesso] Artesanato Indígena do Amazonas. Disponível em: http://sebraemercados.com.br/caso-de-sucesso-artesanato-indigena-do-amazonas-2/. Acesso em: 31 mar. 2019. 